\title{
Improved agreement of AIRS tropospheric carbon monoxide products with other EOS sensors using optimal estimation retrievals
}

\author{
J. X. Warner ${ }^{1}$, Z. Wei ${ }^{1}$, L. L. Strow ${ }^{1}$, C. D. Barnet ${ }^{2}$, L. C. Sparling ${ }^{1}$, G. Diskin ${ }^{3}$, and G. Sachse ${ }^{3}$ \\ ${ }^{1}$ Joint Center for Earth Systems Technology, University of Maryland Baltimore County, 5523 Research Park Dr., Suite 320, \\ Baltimore, MD 21228, USA \\ ${ }^{2}$ NOAA NESDIS ORA, 5200 Auth Road, Camp Springs, MD, USA \\ ${ }^{3}$ NASA Langley Research Center, Hampton, VA 23693, USA
}

Received: 7 March 2010 - Published in Atmos. Chem. Phys. Discuss.: 6 May 2010

Revised: 25 September 2010 - Accepted: 28 September 2010 - Published: 8 October 2010

\begin{abstract}
We present in this paper an alternative retrieval algorithm for the Atmospheric Infrared Sounder (AIRS) tropospheric Carbon Monoxide (CO) products using the Optimal Estimation $(\mathrm{OE})$ technique, which is different from the AIRS operational algorithm. The primary objective for this study was to compare AIRS CO, as well as the other retrieval properties such as the Averaging Kernels (AKs), the Degrees of Freedom for Signal (DOFS), and the error covariance matrix, against the Tropospheric Emission Spectrometer (TES) and the Measurement of Pollution in the Troposphere (MOPITT) $\mathrm{CO}$, which were also derived using the OE technique. We also demonstrate that AIRS OE CO results are much more realistic than AIRS V5 operational CO, especially in the lower troposphere and in the Southern Hemisphere ( $\mathrm{SH}$ ). These products are validated with in situ profiles obtained by the Differential Absorption Carbon Monoxide Measurements (DACOM), which took place as part of NASA's Intercontinental Chemical Transport Experiment (INTEX-B) field mission that was conducted over the northern Pacific in Spring 2006. To demonstrate the differences existing in the current operational products we first show a detailed direct comparison between AIRS V5 and TES operational V3 CO for the global datasets from December 2005 to July 2008. We then present global CO comparisons between AIRS OE, TES V3, and MOPITT V4 at selected pressure levels as well as for the total column amounts. We conclude that the tropospheric CO retrievals from AIRS OE and TES V3 agree to within 5-10 ppbv or 5\% on average globally and throughout the free troposphere. The agreements in total column CO amounts between AIRS OE and MOPITT V4 have improved significantly compared to AIRS V5 with global relative RMS differences now being $12.7 \%$.
\end{abstract}

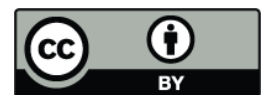

Correspondence to: J. X. Warner (juying@umbc.edu)

\section{Introduction}

Satellite measurements of atmospheric chemical constituents have enhanced our understanding of how natural and human activities affect climate and air quality in the earth system. The monitoring of tropospheric Carbon Monoxide (CO), identified as a good pollution tracer and a precursor of ozone, provides significant value in air quality studies. Three sensors on NASA Earth Observing System (EOS) satellites, the Measurement of Pollution in the Troposphere (MOPITT) on Terra, the Atmospheric Infrared Sounder (AIRS) on Aqua, and the Tropospheric Emission Spectrometer (TES) on Aura, have been making global CO measurements since 2000, and these products have been successfully used in many transport studies (Edwards et al., 2006; Zhang et al., 2006; Stohl et al., 2007; Pfister et al., 2010; Fisher et al., 2010), Chemical Transport Model (CTM) validations and inverse modeling studies (Kopacz, et al., 2010; Nam et al., 2010; Turquety et al., 2008), data assimilation (Lamarque et al., 2004; El Amraoui et al., 2010; Tangborn et al., 2009), and intercomparisons with other $\mathrm{CO}$ measurements (Warner et al., 2007; Luo et al., 2007a; Yurganov et al., 2008; Emmons et al., 2009). It is important to examine the consistency of these sensors, so that the measurements can be used collectively to provide greater temporal and spatial coverage than individual sensors. It is challenging, however, to compare products derived from these sensors because the differences are due to many factors including instrument characteristics, retrieval methods, and natural variability.

The AIRS instrument on Aqua was launched in 2002 with its primary goal of determining the vertical profiles of temperature and water vapor in the earth's atmosphere to improve weather forecasts, as well as for climate monitoring (Aumann, et al., 2003). CO retrievals are obtained from the $2160-2200 \mathrm{~cm}^{-1}$ portion of the spectrum on the edge of the $1-0$ vibration-rotation band of $\mathrm{CO}$ with a spectral spacing

Published by Copernicus Publications on behalf of the European Geosciences Union. 
of $\sim 1.8 \mathrm{~cm}^{-1}$ and an instrument Noise Equivalent Differential Temperature (NeDT) at typically $0.14 \mathrm{~K}$ (McMillan et al., 2003). Due to its wide swaths at $1600 \mathrm{~km}$ cross track and cloud clearing that recovers up to $80 \%$ of cloudy coverage, AIRS orbit covers the globe approximately twice a day (Susskind et al., 2003). The cloud-clearing process increases the global coverage significantly, however, it reduces the spatial resolution from AIRS single Field-Of-Views (FOVs) of approximately $15 \times 15 \mathrm{~km}^{2}$ to the spatial resolution of the Advanced Microwave Sounding Unit (AMSU) at approximately $45 \times 45 \mathrm{~km}^{2}$. The AIRS operational retrieval uses an information-based method described by Susskind et al. (2003). Warner et al. (2007) summarized AIRS version 4 (V4) CO validation results against NASA Intercontinental Chemical Transport Experiment-North America (INTEXNA) field campaign data (Singh et al., 2004) and concluded that in the mid-troposphere AIRS operational V4 CO products agree with in situ measurements to within 20 parts per billion volume (ppbv) or $10 \%$ over the US. They further concluded that the performance of AIRS CO profile retrievals in the Northern Hemisphere (NH) mid-troposphere is comparable with MOPITT V3 CO profiles in the same region. Yurganov et al. (2008) summarized the comparison of CO total column measurements between AIRS, MOPITT and two ground spectrometers, and concluded that AIRS data (V4) for biomass burning events are in agreement or lower than both MOPITT (V3) and ground measurements, but CO enhancements can be seen by AIRS in most cases.

The TES instrument (Beer, et al., 2006) is an imaging infrared Fourier Transform Spectrometer with both nadir and limb-viewing capability covering the spectral range 650$3050 \mathrm{~cm}^{-1}$ at either $0.08 \mathrm{~cm}^{-1}$ or $0.02 \mathrm{~cm}^{-1}$ spectral sample spacing. TES has higher spatial and spectral resolution compared to AIRS, however, lower Signal-to-Noise Ratio (SNR) $(\mathrm{NeDT}$ of $1.5 \mathrm{~K}$ at $300 \mathrm{~K})$ and lower global coverage with nadir only pixels at $5 \times 8 \mathrm{~km}^{2}$. TES CO retrievals, which use spectral regions of $2080-2180 \mathrm{~cm}^{-1}$ (Worden et al, 2004), are based on the Optimal Estimation (OE) technique described by Rodgers (2000) and use MOZART (Model of Ozone and Related Tracers, Brasseur et al., 1998) model profiles as the prior information. Luo, et al. (2007b) summarized TES CO validation using the Intercontinental Chemical Transport Experiment: MILAGRO and Pacific phases (INTEX-B) (Singh et al., 2008) (http://www.espo.nasa.gov/ intex-b) differential-Absorption Carbon Monoxide Measurements (DACOM) (Sachse et al., 1987) in situ profiles. They pointed out that for certain types of $\mathrm{CO}$ distributions, such as during the Houston, TX portion of the experiment, the difference between TES and DACOM CO observations is smaller than the variability of both the TES $(10-15 \%$ the standard deviations (SDV)) and DACOM measurements (15$20 \%$ SDV), while in other areas, the differences could be as large as $\pm 35 \%$.
MOPITT was specifically designed to measure the tropospheric carbon monoxide and methane by using the cell correlation technique as described by Drummond (1989). The CO information is obtained from the spectral region at $4.7 \mu \mathrm{m}$ with a spatial nadir resolution of $22 \times 22 \mathrm{~km}^{2}$. The MOPITT retrieval algorithm follows the OE method and for version 3 (V3) and the earlier versions the retrieval method was discussed by Pan et al. (1998) and Deeter et al. (2003). The MOPITT latest version (V4) has been delivered recently and it adapts to use a set of dynamic a priori profiles, in $2.8 \times 2.8$ degree grids computed from the monthly mean MOZART profiles, and a fixed covariance matrix (Deeter et al., 2010). MOPITT V4, like TES, also uses log-normal volume mixing ratios (VMRs) for the state variable vertical distribution as opposed to the previously used (in V3) VMR values for the CO vertical distribution. Deeter et al. (2010) also summarized the retrieval improvements for $\mathrm{V} 4$ due to other factors such as the slow instrument drift first pointed out by Emmons et al. (2009). MOPITT CO products have been established as well-recognized reference sources after being validated against a variety of in situ measurements: V3 by Emmons et al. (2004, 2007, 2009) and V4 by Deeter et al. (2010).

For nadir-viewing satellite instruments using the thermal spectral regions, the trace gas measurements may have little sensitivity in certain vertical portions of the atmosphere. For example, near the earth surface, prior information for the trace gases is needed in the retrieval algorithm. To identify the true measurement gained from satellite retrievals, the vertical sensitivities of the retrievals need to be considered (Rodgers and Connor, 2003). Furthermore, to understand the $\mathrm{CO}$ retrievals from multiple instruments we need to understand the factors affecting retrievals, such as the Averaging Kernels (AKs), Degree of Freedom for Signal (DOFS), error covariance matrix, etc. Because these quantities in the AIRS operational algorithm are obtained using a formulation (Maddy et al., 2008) that is different from that used in the OE method, a proper comparison of the sensors requires that we use the same retrieval method.

We present in this paper an alternative retrieval algorithm for the AIRS tropospheric CO product using an OE technique that is formulated as closely as possible to that used by MOPITT and TES. We will demonstrate that AIRS OE CO results are much more realistic than AIRS V5 operational CO, especially in the lower troposphere regions and in the Southern Hemisphere (SH). These products are validated with in situ profiles obtained by DACOM measurements, which took place as part of INTEX-B. In Sect. 2, we first show a detailed comparison between AIRS V5 and TES operational CO for the global datasets during the December 2005 to July 2008 period to demonstrate the large differences existing in the current operational products. In Sect. 3, we document the mathematical formulations used by both AIRS V5 operational algorithm and the AIRS OE technique. In Sect. 4, we will present AIRS OE CO retrievals and the comparisons with AIRS operational V5 CO profiles. We also include 

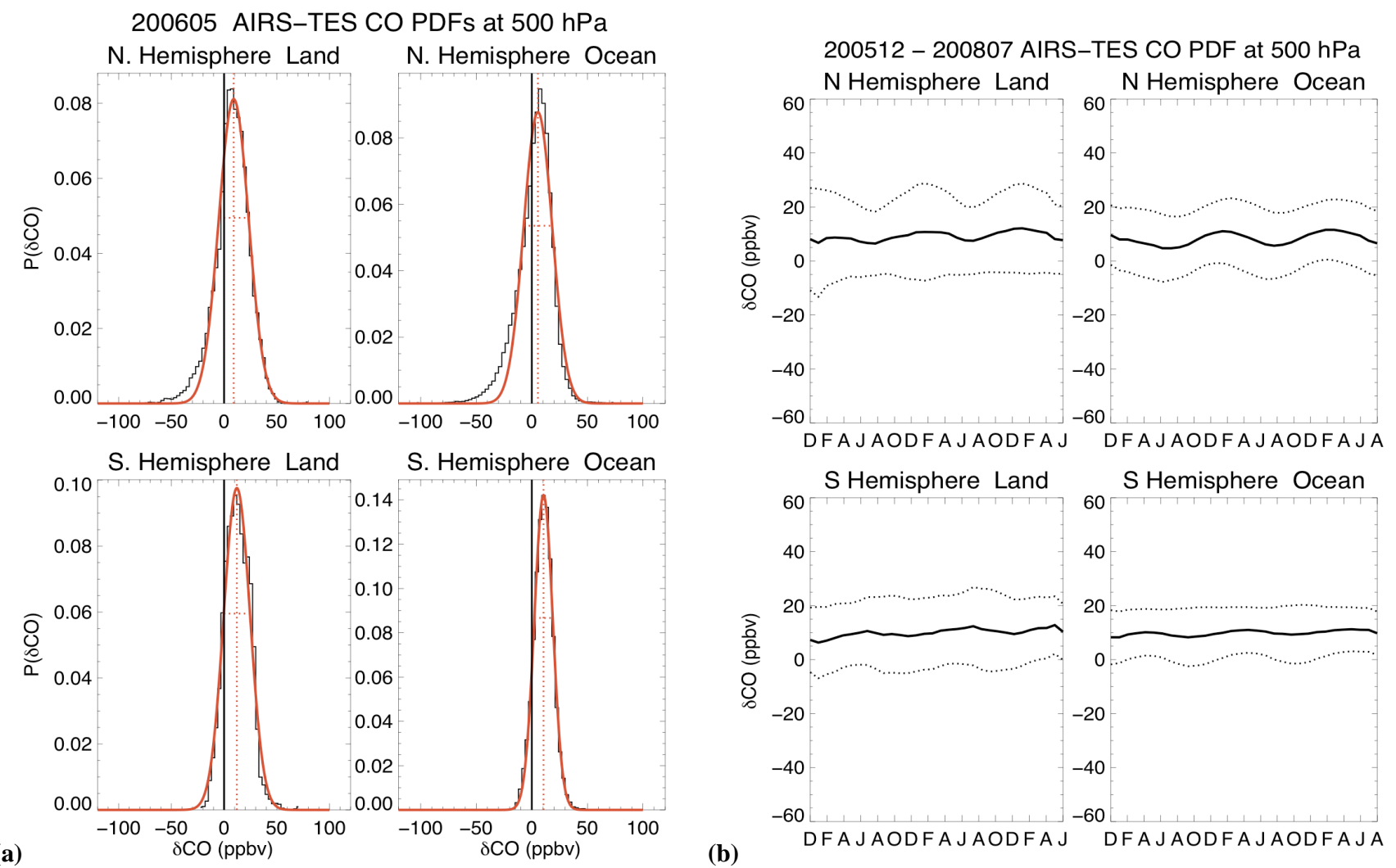

Fig. 1. (a) An example of the CO VMRs (ppbv) difference PDFs at $500 \mathrm{hPa}$ between AIRS V5 operational and TES V3 products for May 2006 over the NH land (top left), NH ocean (top right), SH land (bottom left), and SH ocean (bottom right). The PDFs are depicted as the thin black histograms and the red solid curves are the Gaussian function fits to the PDFs for each area. The vertical red dotted lines at the centers of the Gaussian functions are the modes of the function and the horizontal red dotted lines are the FWHMs of the Gaussian fits indicating the SDVs of the dataset. (b) The time series of the biases and the SDVs of the monthly Gaussian fits to the PDFs of the CO VMR differences at $500 \mathrm{hPa}$ between AIRS V5 operational and TES V3 products for the period of Dec. 2005 to July 2008 for NH land (top left), $\mathrm{NH}$ ocean (top right), SH land (bottom left), and SH ocean (bottom right), respectively. Solid curves show the biases of the Gaussian fits and the dotted curves mark the bounds of the SDVs.

validations of $\mathrm{CO}$ profiles using in situ measurements from the DACOM instrument onboard DC-8 during the INTEX-B experiment. We then present the global CO comparisons between AIRS, MOPITT, and TES at the selected levels and for the total column amounts before summarizing our results.

\section{Background: CO differences between AIRS and TES operational products}

AIRS and MOPITT CO comparisons of the operational products were carried out by Warner et al. (2007), and they concluded that the two datasets agree to within approximately $10 \%$ or $20 \mathrm{ppbv}$ near $500 \mathrm{hPa}$ where the measurement sensitivities are high for both sensors. The differences between the two sensors are much larger in the lower troposphere where the measurement sensitivities are lower. In this section, we will summarize the $\mathrm{CO}$ mixing ratio differences at selected levels between AIRS and TES for a period of approximately 3 years.

We collocated each pair of AIRS and TES pixels by time and geographical location, where the measurements from the two instruments were taken approximately 15 minutes apart, for all available TES data from Dec. 2005 to July 2008, and then summarized the global statistics of the CO profile differences. We define the $\mathrm{CO}$ difference at each vertical level between each AIRS and TES pixel pair as $\delta(\mathrm{CO})=\mathrm{CO}_{\text {AIRS }}{ }^{-}$ $\mathrm{CO}_{\mathrm{TES}}$ and the Probability Distribution Function (PDF) for each monthly ensemble as $P(\delta \mathrm{CO})$ (Sparling, 2000). Figure 1a shows an example of the CO VMRs (ppbv) difference PDFs at $500 \mathrm{hPa}$ for May 2006 over the Northern Hemisphere (NH) land (top left), $\mathrm{NH}$ ocean (top right), Southern Hemisphere (SH) land (bottom left), and SH ocean (bottom right). The PDFs are depicted as the thin black histograms and the red solid curves are the Gaussian function fits to the PDFs for each area. The vertical red dotted lines at the centers of the Gaussian functions are the modes of the function 
and the horizontal red dotted lines are the full-width halfmaxima (FWHMs) of the Gaussian fits indicating SDVs of the dataset. We define the bias as the mode of the distribution of differences, rather than the average, since these differences follow the Gaussian function very well and represent the well-mixed background $\mathrm{CO}$ emissions (Sparling, 2000). For this example the biases are 5 to $10 \mathrm{ppbv}$, with the NH ocean being the smallest and the SH land being the largest, and the SDVs are 10-15 ppbv with the smallest over SH ocean and the largest over NH land.

Figure $1 \mathrm{~b}$ illustrates the time series of the differences between the two products. The biases and the SDVs of the monthly Gaussian fits to the PDFs of the CO VMR differences at $500 \mathrm{hPa}$ are shown for the period of December 2005 to July 2008 for NH land (top left), NH ocean (top right), SH land (bottom left), and SH ocean (bottom right), respectively. Solid curves show the biases of the Gaussian fits and the dotted curves mark the bounds of the SDVs varying with time from December 2005 to July 2008. The CO VMR biases between the two sensors at $500 \mathrm{hPa}$ are below $10 \mathrm{ppbv}$ globally representing a $5-10 \%$ difference in general. In the $\mathrm{NH}$, the seasonal variation of the differences is correlated with the magnitudes of the $\mathrm{CO}$ concentrations, since the $\mathrm{CO}$ differences are larger during the winter-spring phase and smaller during the summer as is the case for the NH CO concentrations. The seasonal variations of the differences are smaller in the $\mathrm{SH}$, and show local peaks associated with strong $\mathrm{SH}$ biomass burning events. The SDVs are also larger when the $\mathrm{CO}$ concentrations are higher and smaller when the $\mathrm{CO}$ concentrations are lower, and range from 10 to $15 \mathrm{ppbv}$.

Figures $2 \mathrm{a}$ and $2 \mathrm{~b}$ show an example of the $P(\delta \mathrm{CO})$ with Gaussian fits at $800 \mathrm{hPa}$ for May 2006 and the time series of the biases and SDVs of the monthly Gaussian fits, respectively. The CO biases between the two sensors at $800 \mathrm{hPa}$ are significantly larger than at $500 \mathrm{hPa}$ except for the $\mathrm{NH}$ ocean cases. In both cases of 500 and $800 \mathrm{hPa}$, the SDVs are lower in the $\mathrm{SH}$ than in the $\mathrm{NH}$. In the $\mathrm{NH}$ over land, the biases range from 0 to $30 \mathrm{ppbv}$ with TES CO higher than AIRS CO, and over the oceans the biases range from -10 to $10 \mathrm{ppbv}$. AIRS CO at $800 \mathrm{hPa}$ in the $\mathrm{SH}$ is uniformly higher than TES CO, with the biases as large as $30-50$ ppbv. The fact that the biases are larger closer to the earth surface is an indication that the sensitivities of the two products, which are due to both instrument characteristics and the algorithms, are very different in the lower troposphere in comparison to the mid-troposphere. Figure $2 b$ also demonstrates that the monthly varying a priori used by TES may have contributed to the increased variability in the time series at $800 \mathrm{hPa}$ since at $800 \mathrm{hPa}$ the CO VMRs are influenced more by the prior for TES than at $500 \mathrm{hPa}$.

\section{Algorithm descriptions}

\subsection{AIRS V5 operational algorithm}

The AIRS V5 algorithm seeks to minimize the weighted difference between the clear column radiance observations and the radiance computed using the AIRS forward model (SARTA) (Strow, et al., 2003) by varying the geophysical state (Susskind, et al., 2003). Furthermore, changes to a set of the geophysical states are represented by a geophysical perturbation parameter and a perturbation function with trapezoidal shapes. An eigenvector decomposition technique is employed in the algorithm to solve for the geophysical state, and a damping process is used to stabilize the solution (Susskind et al., 2003). The selection of the number and levels of the trapezoidal functions, the magnitude of the damping constraint, and the choice of the first guess profile all affect the performance of the retrieval. A subset of 36 spectral channels out of 52 channels in the $\mathrm{CO}$ region is selected for the operational retrievals using principle component analysis. The parameters used in the retrievals for this study are described by the AIRS Version 5.0 Released Files Description (http://disc.sci.gsfc.nasa.gov/AIRS/documentation). Due to the lack of observational sensitivity in certain portions of the atmosphere for thermal sensors, an appreciable amount of the first guess profile often is retained in AIRS CO operational products (Warner et al., 2007). This first guess profile is analogous to the a priori profile in the optimal estimation algorithm. The AIRS first guess for the V5 operational products uses the MOPITT V3 a priori mean profile, adding the Air Force Geophysics Laboratory (AFGL) climatology for the levels above $10 \mathrm{hPa}$. Based on Rodgers and Connor (2003), an estimated profile from a retrieval algorithm is represented as the combination of a true profile and an a priori profile through the knowledge of an averaging kernel. The AIRS operational averaging kernel, shown as the A matrix in Eq. (1), indicates the sensitivity of the measurements to the CO concentrations at the retrieval levels defined by the trapezoids (Susskind, et al., 2003). The details of the derivation and application of the averaging kernels was discussed by Maddy et al. (2008), and also documented at NASA Goddard Earth Sciences Data and Information Services Center (GES DISC). The convolution of an in situ profile uses the following formula for AIRS V5:

$\boldsymbol{x}^{\prime}=\boldsymbol{x}_{0}\left[1+\mathbf{A}\left(\frac{\boldsymbol{x}-\boldsymbol{x}_{0}}{\boldsymbol{x}_{0}}\right)\right]$

where $\mathbf{A}$ stands for the averaging kernel, $\boldsymbol{x}^{\prime}$ represents the transformed in situ profile, $\boldsymbol{x}$ is the true profile, and $\boldsymbol{x}_{0}$ is the first guess profile. Equation (1) is used to convolve the in situ DACOM profiles in the comparisons with AIRS operational retrievals as described in the following section. 

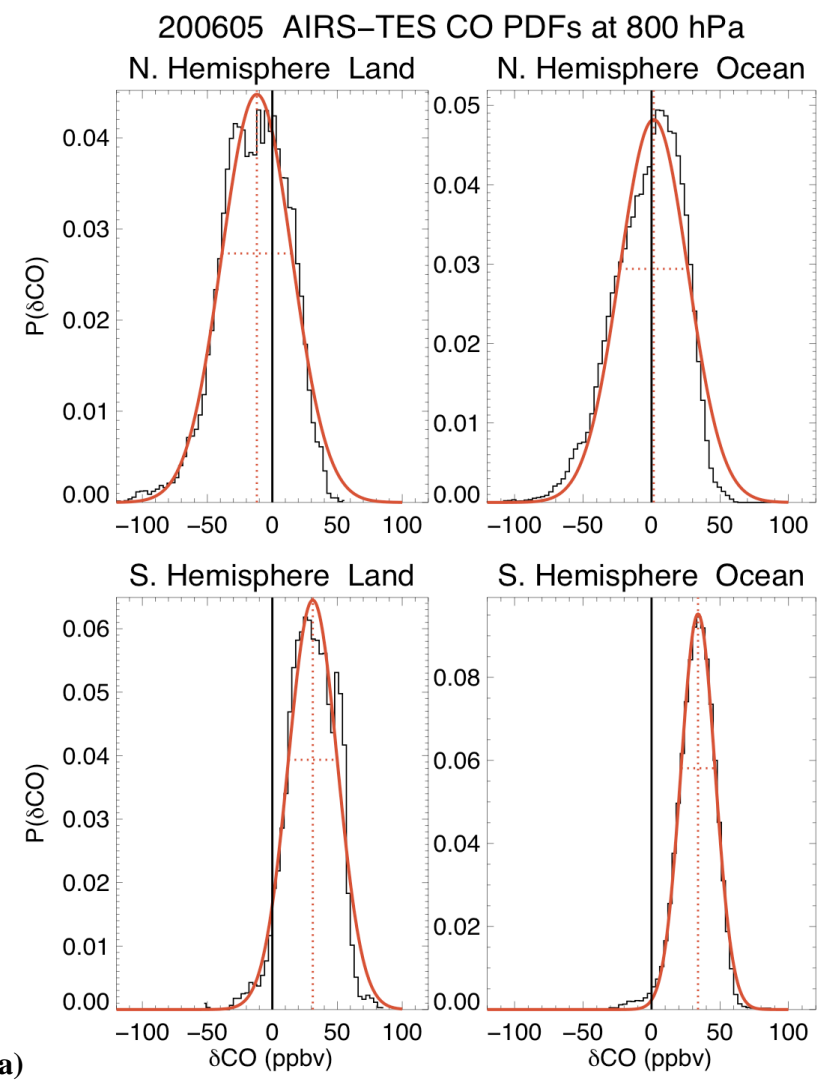
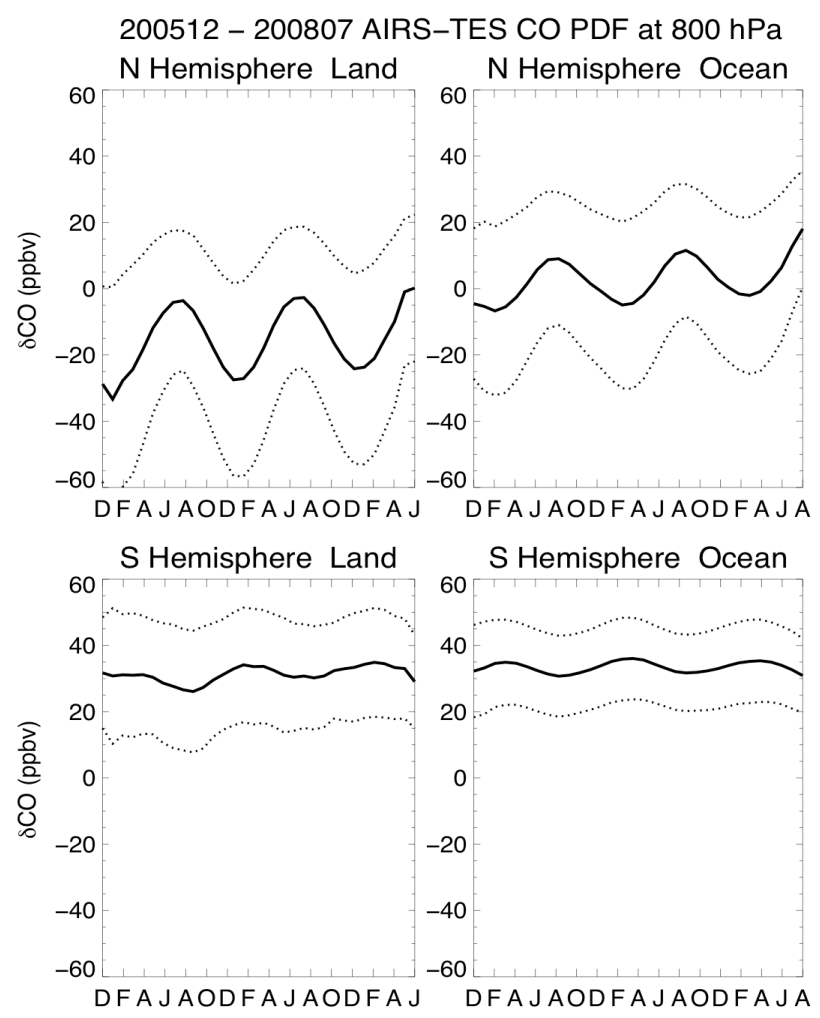

(b)

Fig. 2. (a) Same as in Fig. 1a but at $800 \mathrm{hPa}$. (b) Same as in Fig. $1 \mathrm{~b}$ but at $800 \mathrm{hPa}$.

\subsection{Optimal Estimation method}

To use the Optimal Estimation (OE) method in AIRS retrievals we follow the formulations given by Rodgers (2000), and also described by Pan et al., (1998). Given a model of the instrument's signals, the forward equation for the $\mathrm{CO}$ profile retrieval problem can be written as

$\boldsymbol{y}=f(\boldsymbol{x}, \boldsymbol{b})+\boldsymbol{n}_{\varepsilon}$,

where $\boldsymbol{y}$ is the vector of measured radiances, $\boldsymbol{x}$ is the state vector (variables to be retrieved from the measurements), $b$ represents all other parameters used by the forward model, $f$ $(\boldsymbol{x}, \boldsymbol{b})$ is the forward model function, and $\boldsymbol{n}_{\varepsilon}$ is the instrument noise.

The meteorological parameters, such as pressures, temperatures, the profiles of constituents other than $\mathrm{CO}$, and the surface parameters are retrieved in the earlier steps of the AIRS operational retrieval system and used as input to the forward model. The retrieval methods for atmospheric variables other than $\mathrm{CO}$ are described in Sect. 3.1. The retrieval process inverts Eq. (2) to find $\boldsymbol{x}$ for a given $\boldsymbol{y}$. As in the case of atmospheric remote soundings, the inverse problem is usually ill posed, because the number of independent measurements is less than the number of variables to be retrieved. The OE method introduces the a priori information as an additional constraint. The solution then can be understood as the combination of the present measurements and the prior knowledge.

For the variables that obey a Gaussian distribution, this inverse problem is equivalent to the maximum likelihood solution, and by using a Newtonian iteration, the solution to Eq. (2) can be written as (Rodgers, 2000 and Pan et al., 1998):

$\boldsymbol{x}_{n+1}$

$=\boldsymbol{x}_{a}+\mathbf{C}_{a} \mathbf{K}_{n}^{T}\left(\mathbf{K}_{n} \mathbf{C}_{a} \boldsymbol{K}_{n}^{T}+\mathbf{C}_{e}\right)^{-1}\left[\boldsymbol{y}-\boldsymbol{y}_{n}-\mathbf{K}_{n}\left(\boldsymbol{x}_{a}-\boldsymbol{x}_{n}\right)\right]$

where $n$ is the order of iteration and $\mathbf{C}_{e}$ is the measurement error covariance matrix. $\mathbf{K}_{n}$ is the Jacobian matrix for iteration $n, \boldsymbol{x}_{a}$ is the mean of the a priori distribution, and $\mathbf{C}_{a}$ is the a priori covariance matrix for $\boldsymbol{x}_{a}$. We used the a priori matrix developed by MOPITT version 3 (Deeter et al., 2003) in this study.

Similar to the averaging kernel discussion in the previous section, it is important to apply the averaging kernel information in the sensitivity analyses using the OE method. As defined by the retrieval formulations, the averaging kernels are computed using the following: 
$\mathbf{A}=\mathbf{C}_{a} \mathbf{K}^{T}\left(\mathbf{K C}_{a} \mathbf{K}^{T}+\mathbf{C}_{e}\right)^{-1} \mathbf{K}$

and,

$\boldsymbol{x}^{\prime} \cong \mathbf{A} \boldsymbol{x}+(\mathbf{I}-\mathbf{A}) \boldsymbol{x}_{a}$,

where $\mathbf{I}$ represents the identity matrix and $\boldsymbol{x}$ is the true state. Equation (5) states that in the absence of other error sources the retrieved state is a weighted mean of the true state and the a priori state, with the weight $\mathbf{A}$ for the true state and I-A for the a priori. This shows the importance of averaging kernels as diagnostics of the retrieval. The closer the matrix $\mathbf{A}$ is to the identity matrix the better the retrieved state resembles the true state. Equation (5) also shows that unless the matrix $\mathbf{A}$ is an identity matrix, each layer of the retrieved state is an averaged contribution of multiple layers in the true state and the a priori state.

\section{AIRS CO retrievals using OE}

As stated in Sect. 2, the agreement between AIRS V5 and TES CO is best in the NH mid-troposphere and the largest differences are in the lower troposphere and in the SH. We discuss, in this section, the advantage of using OE for AIRS $\mathrm{CO}$ retrievals and the improved agreements between AIRS and TES where the two operational products differ the most. We are using AIRS operational codes as the base line for this study and only changing the minimization formulations for the $\mathrm{CO}$ retrievals by using the OE method. Therefore, the same cloud cleared radiances and noise are used in the AIRS OE retrievals as in the AIRS V5 operational algorithm. The measurement error covariance matrix was constructed to include the instrument NeDT, and the computed noise resulting from errors in estimated cloud-cleared radiance, surface skin temperature and emissivity, temperature and moisture profiles, etc. (see Susskind et al., 2003). The treatment for all other state variables retrieved before $\mathrm{CO}$, such as temperature, water vapor, ozone, cloud, and surface properties, etc. are also kept the same as in the AIRS V5 operational products. This will facilitate the comparisons between the two retrieval algorithms for $\mathrm{CO}$ without introducing additional complicating factors.

For comparison purposes, we list in Table 1 the prior information used for AIRS OE, V5, MOPITT V3, V4, and TES as either a form of first guess (X) or a priori (Y). The a priori used for AIRS OE is the same as the MOPITT V3 global uniform a priori, which includes both the mean profile and the covariance matrix. AIRS V5 only uses a first guess (not a priori), which is equal to the mean profile of AIRS OE or MOPITT V3 a priori. TES uses a set of monthly mean a priori profiles, averaged over several areas over the globe, with a fixed covariance matrix (Kulawik et al., 2006 and Luo et al., 2007). MOPITT V4 recently adapted to use a set of monthly mean a priori profiles, in $2.8 \times 2.8$ degree grids from the MOZART climatology and interpolated to measurement locations, and a fixed covariance matrix (Deeter et al., 2010). Although all of these retrievals use a first guess it does not contribute to the final results in the OE method, except for the case of AIRS V5. In addition, the AIRS OE CO retrievals are performed in 34 retrieval layers to strike a balance between the computational time, retrieval stability, and the smoothness of output profiles, etc. AIRS V5 CO VMRs in the standard products are output at 9 vertical levels. TES CO VMR products are at 67 levels, and MOPITT V3 CO VMRs are output at 7 levels, while the MOPITT V4 products are on 10 pressure levels.

Figure $3 \mathrm{a}$ and $\mathrm{b}$ show two $\mathrm{CO}$ profiles collected during INTEX-B from DC-8 spirals on 4 March 2006 at 20:33:37 (left panel) and 18:10:30 UTC time (right panel) where the in situ measurements from DACOM are depicted by the green curves. This geographical region on that particular day was affected by agricultural fires in the southeast US, which resulted in high CO concentrations in the lower troposphere. The spiral profile on the left panel was collected over the Gulf of Mexico and the one on the right was collected over land to the west of Birmingham, AL, near the fires. The dark blue curves in Fig. 3a depict AIRS V5 CO profiles using the operational retrieval algorithm and the cyan curves are the in situ profiles convolved to AIRS V5 CO using Eq. (1). The red curves represent the OE CO profiles and the orange curves are the in situ profiles convolved to the OE retrieval space using Eq. (5). In general, the differences between the retrievals and the convolved in situ profiles using the AKs given by the retrieval algorithm indicate how well a remote sensor measures an atmospheric property. In this sense, the two algorithms provide similar information where the AIRS instrument is sensitive to $\mathrm{CO}$, namely in the mid-troposphere, where the retrievals agree with the in situ measurements to within 5-10 ppbv as shown in Fig. 3a. The OE algorithm provides some slight improvement as shown by the differences between the red and orange curves in comparison with the blue and cyan curves. The OE technique leads to significantly greater agreement between the retrievals and the in situ profiles in the lower troposphere, especially below $800 \mathrm{hPa}$, even though the retrieved minus convolved differences for the two algorithms are similar. The much more realistic results for the AIRS OE CO, compared to the in situ profiles, are largely due to how the a priori information is used in the retrieval algorithm. The OE method constrains the retrieved profiles to the a priori, whereas AIRS operational results converge to the first guess where the measurement information is lacking. This constraint to the $\mathrm{CO}$ a priori profile in the OE retrievals is largely determined by the a priori correlation distance, which could influence the $\mathrm{CO}$ retrievals in the lower troposphere. See Deeter et al. (2010) for a thorough discussion on the differences between MOPITT $\mathrm{V} 3$ and $\mathrm{V} 4 \mathrm{CO}$ products.

In an attempt to understand the implications of the above differences, we show in Fig. 3b the SDVs for AIRS V5 (blue) and OE (red) $\mathrm{CO}$ retrievals within $200 \mathrm{~km}$ radius 
Table 1. A priori information used in the retrievals of related satellite products.

\begin{tabular}{|c|c|c|}
\hline Method & First Guess & A Priori \\
\hline AIRS OE & & 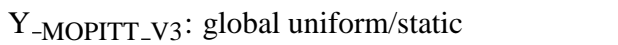 \\
\hline AIRS V5 & $\mathrm{X}=\mathrm{MEAN}\left(\mathrm{Y}_{-\mathrm{MOPITT}} \mathrm{V} 3\right)$ & N/A \\
\hline MOPITT V3 & & 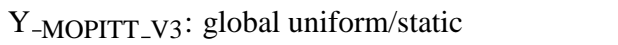 \\
\hline MOPITT V4 & & Y_MOPITT_V4 $_{\text {- monthly mean MOZART profiles }}$ \\
\hline TES & & Y-TES: monthly mean MOZART profiles \\
\hline
\end{tabular}

(a)
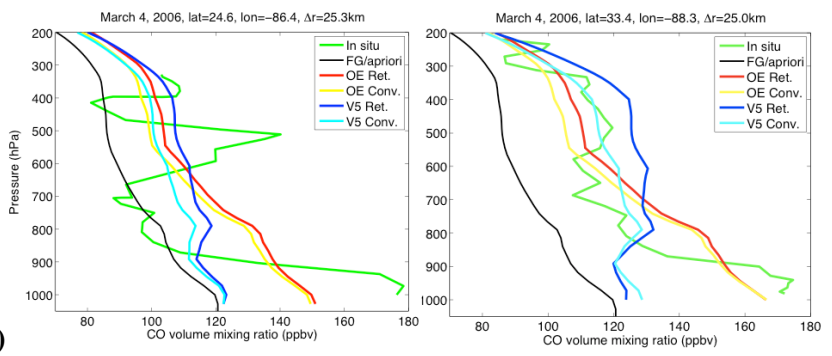

(b)

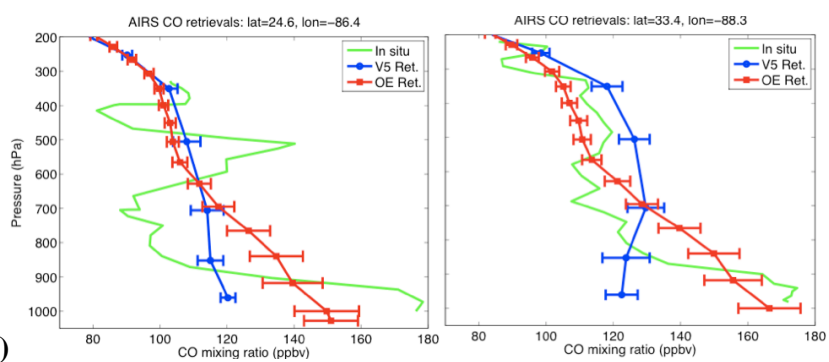

Fig. 3. (a) INTEX-B DC-8 spiral profiles on 4 March 2006, over Gulf of Mexico (left) and over land to the west of Birmingham, AL near the fires (right), collocated with AIRS V5 CO (blue and cyan lines) and AIRS OE CO (red and orange lines). Cyan curves show the convolved in situ $\mathrm{CO}$ profile to the V5 retrievals and the orange curves show that convolved to the OE retrievals. (b) Similar to Fig. $3 \mathrm{a}$ except that Fig. $3 \mathrm{~b}$ also shows the SDV values for AIRS OE and V5 CO retrievals within $200 \mathrm{~km}$ circles surrounding the in situ profiles.

circles surrounding the same in situ profiles as in Fig. 3a. These SDVs range from $\sim 10 \mathrm{ppbv}$ in the mid-troposphere to $\sim 20$ ppbv in the lower troposphere for AIRS OE, which represent approximately $10 \%$ of the CO VMRs for these cases, and meanwhile, the variability of AIRS V5 is smaller in the lower troposphere. Based on this discussion we conclude that the differences between the convolved in situ measurements and the AIRS OE CO retrievals are very close to the range of the variations in the retrieved values. Another factor related to the retrieval uncertainty is the percentage contribution from the a priori used in the retrieval, and hence, we examine the AIRS OE error covariance matrix relative to the a priori variance in each retrieval layer for the same cases shown in Fig. 3. The CO VMR percent a priori is approximately $30-40 \%$ in the free troposphere $(300-850 \mathrm{hPa})$ (figures not shown) and increases sharply above and below this vertical region indicating reduced measurement sensitivity. Sixty to seventy percent of the AIRS OE retrieved CO VMRs are from the AIRS instrument, which is consistent with MOPITT V3 values (not shown).

We have produced full-day retrievals for AIRS CO using OE for the period of Jan. to June 2006 and compared these retrievals with the collocated TES CO profiles. Note that TES CO was retrieved using the OE algorithm and a globally varying a priori developed from the MOZART model. A typical NH CO profile comparison is shown in Fig. 4 from the retrievals on 4 March 2006. The black curve on the top panel represents the first guess, and/or the mean a priori profile, which is the same as MOPITT V3 globally uniform a priori. The dark blue curve on the top panel represents the 9-level AIRS V5 CO from NASA/DAAC, the red curve represents the AIRS OE CO, and the green line shows the collocated TES CO profile. All three retrieved CO profiles agree well (within approximately $10 \mathrm{ppbv}$ ) in the midtroposphere $(300-600 \mathrm{hPa})$ region while the differences are significantly larger between AIRS V5 and TES CO closer to the surface. Below $600 \mathrm{hPa}$, AIRS operational retrievals converge towards the first guess since the measurement sensitivities are weaker in these layers, resulting in underestimation in the $\mathrm{NH}$ where the $\mathrm{CO}$ emissions are stronger in this season. AIRS OE retrievals are constrained largely by the shape of the a priori and result in much better agreement with TES CO. Similarly, a typical SH CO profile is shown in Fig. 5 for 4 March 2006. The AIRS V5 overestimates the $\mathrm{CO}$ VMRs in the $\mathrm{SH}$ where the $\mathrm{CO}$ concentrations are significantly lower than the first guess/a priori. The AIRS OE CO retrievals agree with TES CO very well in the entire tropospheric column down to $850 \mathrm{hPa}$ for both $\mathrm{NH}$ and $\mathrm{SH}$ profiles.

The bottom panels in Figs. 4 and 5 show the AKs for AIRS V5 (dashed) and OE (solid). The OE AKs are shown at selected layers from the 34 retrieval layers to match the pressure levels of the V5 AKs that use a total of 9 retrieval layers, and therefore, the $\mathrm{OE} \mathrm{AKs}$ represent thinner layers than the V5 AKs. The correct quantitative comparison is to use the AKs normalized by a layer thickness (Deeter et al., 2007), but, however, we are only aiming to demonstrate the vertical position where the measurement information is taken. As shown in the AKs, the main measurement 

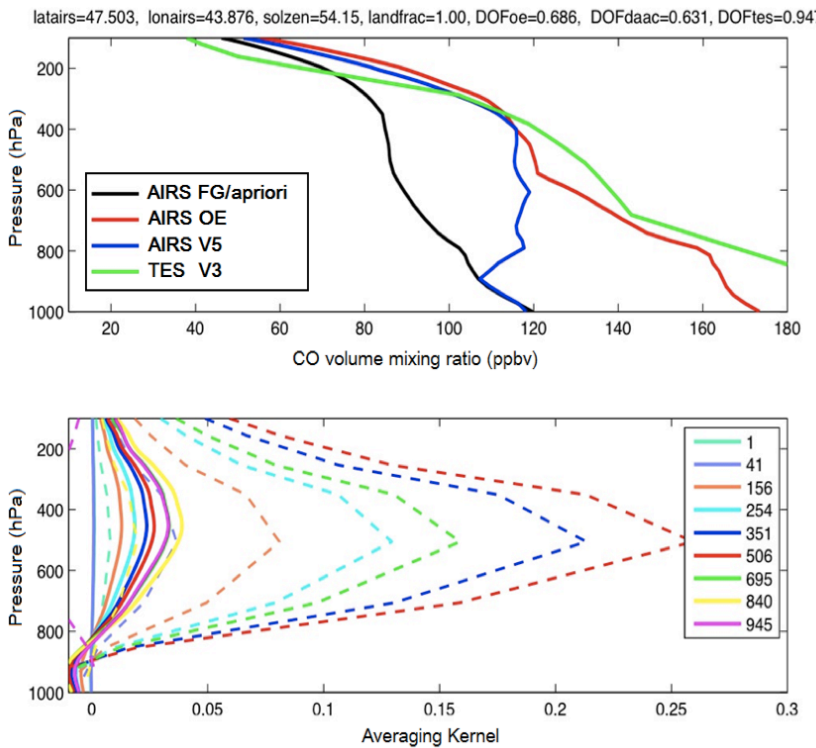

Fig. 4. A typical NH CO profile comparison from the retrievals on 4 March 2006, where the black curve on the top panel represents the first guess for V5 and the mean OE a priori profile. The dark blue curve on the top panel represents the 9-level AIRS V5 CO from NASA/DAAC, the red curve represents the AIRS OE CO, and the green line shows the collocated TES CO profile. The bottom panel shows the AKs from the V5 retrievals (dashed) and from the $\mathrm{OE}$ (solid) at pressure levels (hPa) identified by the legend.
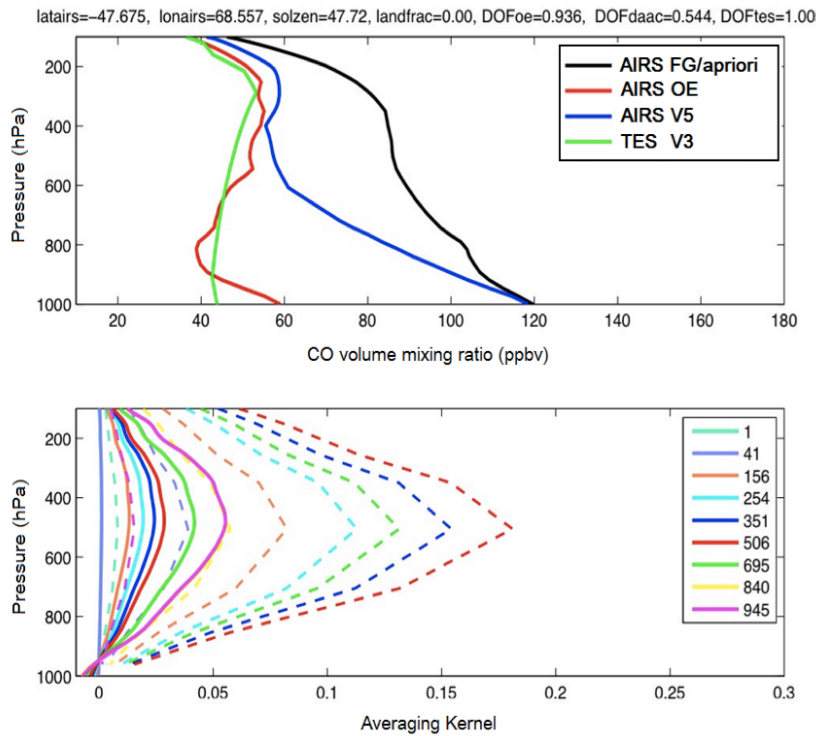

Fig. 5. As in Fig. 4 except for the SH.

information is obtained in the mid-troposphere between 400 and $600 \mathrm{hPa}$ for both the AIRS operational algorithm and the OE.

Using OE for AIRS improves the accuracy of the lower troposphere $\mathrm{CO}$ retrievals and the retrievals in clean atmo-
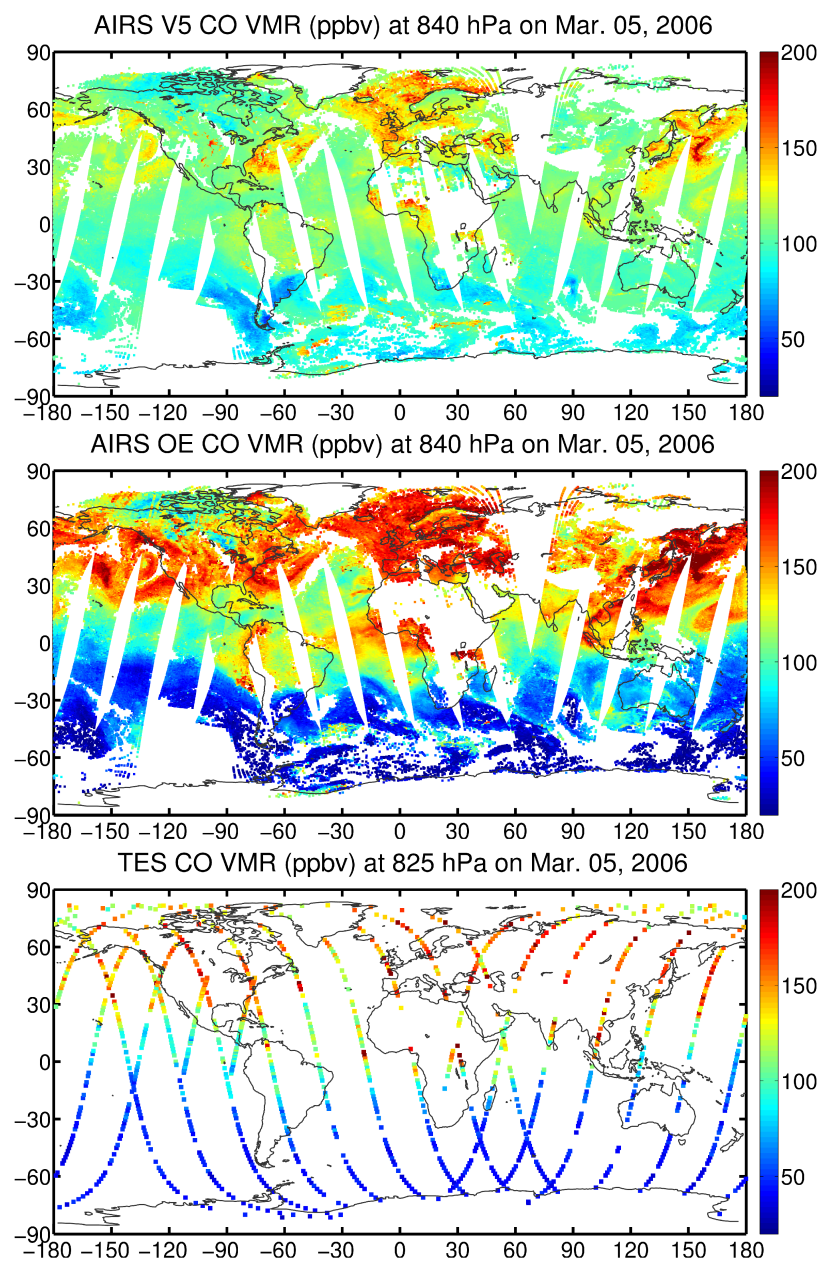

Fig. 6. The comparisons of the global CO maps in the lower troposphere where the red/blue colors indicate relatively high/low values. The top panel shows AIRS V5 CO at $840 \mathrm{hPa}$ on 5 March 2006, the middle panel shows AIRS CO at the same level but retrieved using the OE technique, and the bottom panel shows TES CO at a similar level.

spheric regions such as the $\mathrm{SH}$. This is best demonstrated by the comparisons of the global $\mathrm{CO}$ maps in the lower troposphere as shown in Fig. 6. The top panel shows AIRS V5 CO at $840 \mathrm{hPa}$, the middle panel shows AIRS CO at the same level but retrieved using the $\mathrm{OE}$ technique, and the bottom panel shows TES CO at a similar altitude. The $\mathrm{CO}$ in the $\mathrm{NH}$ in the lower troposphere is significantly enhanced, which is explained by the fact that the emissions and the total concentrations in the $\mathrm{NH}$ are high in the spring season. This is also consistent with TES CO (bottom panel) that shows similar values. In the $\mathrm{SH}$, the $\mathrm{OE} \mathrm{CO}$ values are significantly lower than the V5 CO especially over the oceans and at high latitudes. These low values of $\mathrm{CO}$ from AIRS OE are closer to reality in that they are consistent with our prior knowledge for these regions. In addition, the closer agreement with TES suggests that the changes in the retrieval have been correct. To summarize, AIRS CO retrievals using the OE technique 

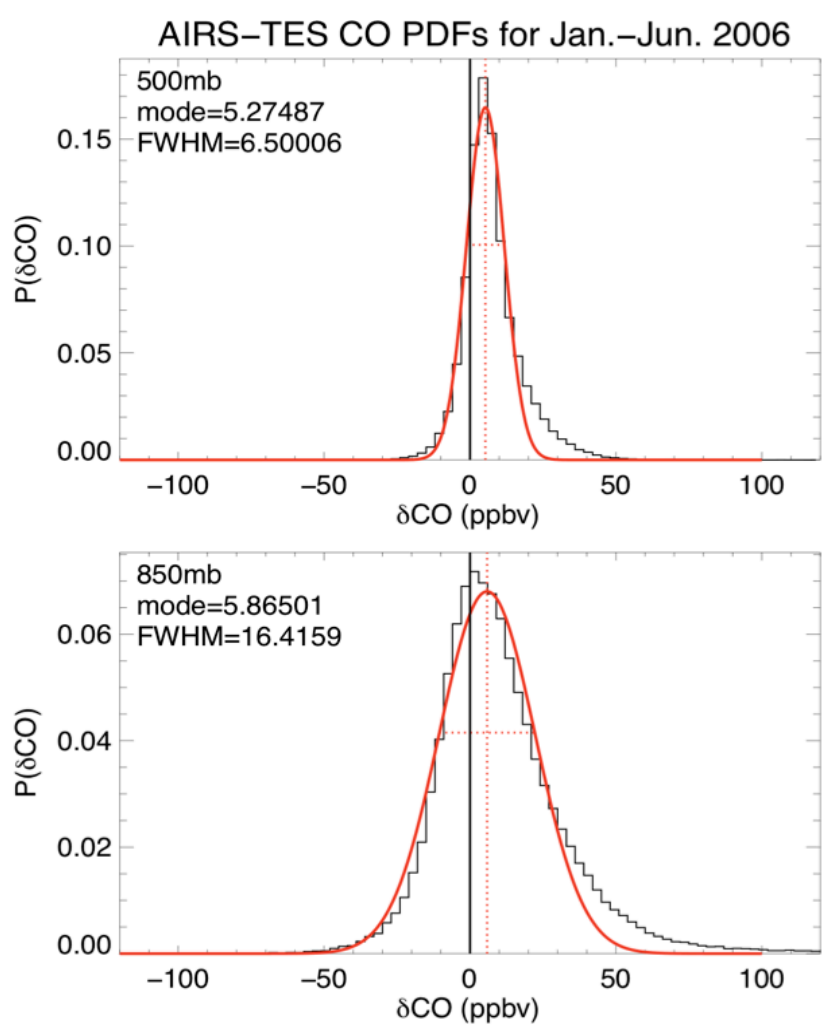

Fig. 7. The PDF and the Gaussian fits of the differences between collocated AIRS OE CO and TES CO convolved to AIRS AKs at 500 and $800 \mathrm{hPa}$, respectively, globally for the period of 1 January to 31 June 2006.

provide more realistic values compared to V5, particularly in the lower troposphere and in the $\mathrm{SH}$.

\section{Comparison of Global Tropospheric CO of AIRS OE with TES and MOPITT}

We have computed the PDF analyses of the differences between AIRS OE CO and TES CO in a same manner as described in Sect. 2. Figure 7 shows the PDF and the Gaussian fit properties of the differences between AIRS OE and TES $\mathrm{CO}$ convolved to AIRS AKs at $500 \mathrm{hPa}$ and $800 \mathrm{hPa}$, respectively, globally for the period of Jan. 1 to June 31, 2006. To reduce the differences in smoothing errors between AIRS OE and TES CO retrievals, we use AIRS OE averaging kernels to smooth TES CO profiles as suggested by Rodgers and Connor (2003). The global bias at $500 \mathrm{hPa}$ represented by the mode of the Gaussian fit is $5.28 \mathrm{ppbv}$ with a SDV of $6.50 \mathrm{ppbv}$ represented by the FWHMs. Similarly, the bias is $5.87 \mathrm{ppbv}$ and the SDV is $16.42 \mathrm{ppbv}$ at $850 \mathrm{hPa}$. To demonstrate these differences, we also list the modes and FWHMs of the Gaussian fits to the CO VMRs difference PDFs at 500 and $800 \mathrm{hPa}$ between AIRS OE and TES V3 products for the same period over the NH land, NH ocean, SH land, and $\mathrm{SH}$ ocean in Table 2. The biases and SDVs over NH land, SH land, and SH ocean at both 500 and $800 \mathrm{hPa}$ are similar to those of the global cases, however, for $\mathrm{NH}$ land the bias and SDV are much larger. This is also shown by the larger differences at the upper end of the PDFs that are likely associated with the higher NH CO concentrations indicating that AIRS measurements are higher than TES when TES CO was convolved using AIRS AKs. Although the differences between the two sensors using a similar algorithm at $500 \mathrm{hPa}$ are smaller than the differences between the two operational products as illustrated in Sect. 2 (see Fig. 1), the changes are not significant at this vertical level. This is because the AIRS sensor is most sensitive in this vertical range for $\mathrm{CO}$ and both V5 and OE retrievals perform well. The improvements between AIRS and TES CO by using different retrieval methods are most significant in the lower troposphere, i.e. at $840 \mathrm{hPa}$, where the biases have decreased from $\sim 30$ ppbv to $\sim 5$ ppbv.

The comparison of CO total column between AIRS and MOPITT further demonstrates the improved agreement of AIRS CO products using the OE technique to other $\mathrm{CO}$ sensors as shown in Fig. 8. The top left panel shows the monthly mean AIRS V5 CO total columns $\left(\times 10^{17} \mathrm{mols} / \mathrm{cm}^{2}\right)$ for March 2006, the top right shows the same quantities except for AIRS OE CO. The total column CO increases using OE over most of the NH by approximately $10 \%$ or $\sim 10$ $15 \mathrm{ppbv}$ and decreases in the SH by up to $30 \%$. The AIRS OE CO total column amounts are compared with MOPITT V3 (left bottom panel) and V4 (right bottom panel), and although AIRS OE used similar a priori information as in MOPITT V3, the results actually agree better with MOPITT V4. The AIRS OE CO total column amounts agree significantly better with MOPITT V4 CO total column values compared with AIRS V5 with a global relative RMS difference (OEMOPITT V4) now being $12.7 \%$, which was reduced from $20.4 \%$ between AIRS V5 and MOPITT V4. MOPITT CO total column values are higher than AIRS using either the V5 or the OE method, especially at high latitudes in the $\mathrm{NH}$ in this example.

To understand the measurement capability of a sensor for a particular remotely sensed geophysical parameter, one needs to examine the information content defined by the DOFS in the retrievals (Rodgers, 2000). The DOFS, computed by the trace of the AKs, indicates the amount of independent measurement information. Figure 9 shows an example of the DOFS for March 2006 for AIRS V5 CO (blue), AIRS OE CO (red), TES CO (green) and MOPITT CO (black), respectively, where the solid lines are the averaged DOFS in 10-degree latitude bands and the dashed lines represent the maximum and minimum DOFS values in each band. For both MOPITT and TES, the DOFS ranges between 1.2 to 1.5 in the tropical and subtropical regions, and decreases to below 1.0 at mid- and high-latitudes. The average DOFS for AIRS OE CO ranges between 0.8 and 1.0 globally. TES CO DOFS are larger than AIRS in low latitudes partly due to the higher spectral resolution, and partly due 

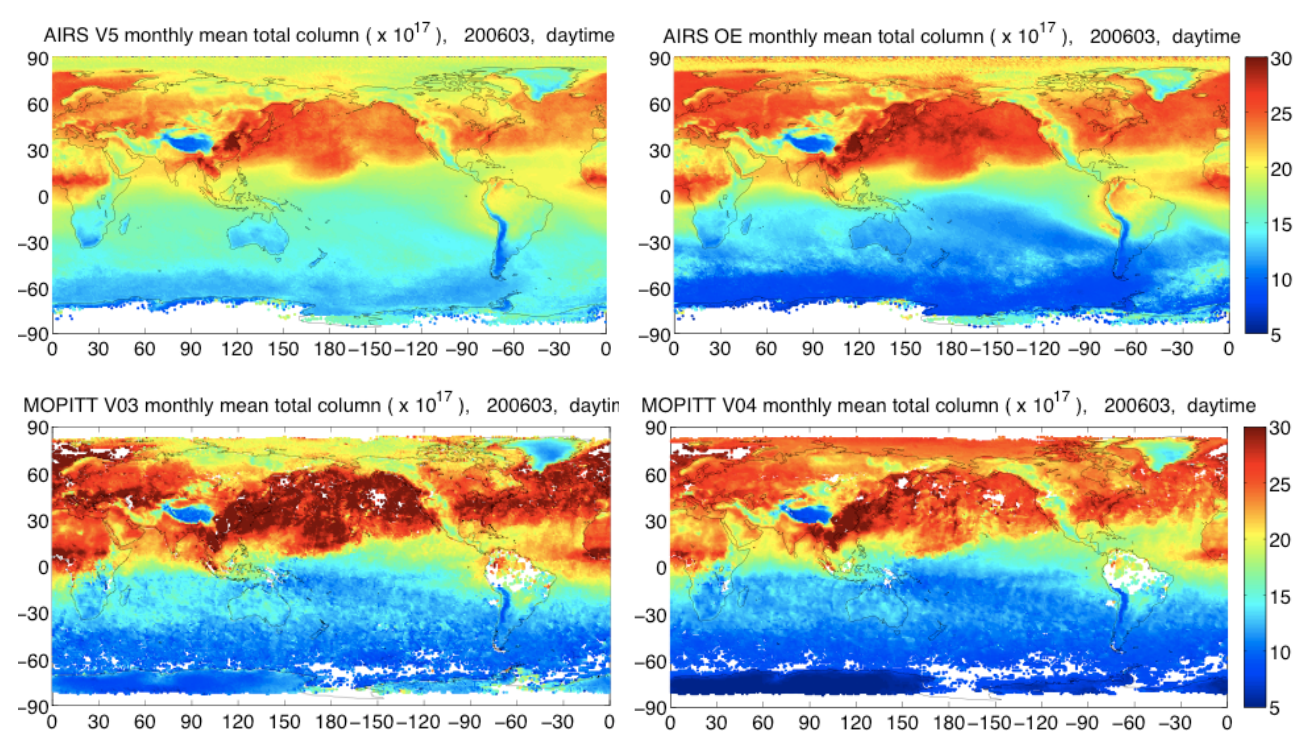

Fig. 8. A comparison of the monthly mean CO total columns $\left(\times 10^{17} \mathrm{mols} / \mathrm{cm}^{2}\right)$ between AIRS V5 (top left), OE (top right), MOPITT V3 (bottom left), and MOPITT V4 (bottom right) for March 2006 where the red/blue colors indicate relatively high/low values.

Table 2. Modes and the full-width half-maxima (FWHMs) of the Gaussian fits to the CO volume mixing ratio difference probability distribution functions at 500 and $800 \mathrm{hPa}$ between AIRS OE and TES V3 products for January to June 2006 over the Northern Hemisphere (NH) land, NH ocean, Southern Hemisphere (SH) land, and SH ocean.

\begin{tabular}{lllll}
\hline & \multicolumn{2}{c}{$500 \mathrm{hPa}$} & \multicolumn{2}{c}{$800 \mathrm{hPa}$} \\
& Mode (ppbv) & FWHM (ppbv) & Mode (ppbv) & FWHM (ppbv) \\
\hline NH Land & 10.6910 & 11.1154 & 17.0903 & 22.6289 \\
NH Ocean & 6.63459 & 8.01672 & 8.87519 & 18.2920 \\
SH Land & 4.04003 & 6.02626 & 3.63266 & 15.4417 \\
SH Ocean & 4.22933 & 4.59482 & 2.00962 & 12.2592 \\
\hline
\end{tabular}

to algorithm differences, since TES CO retrievals use a latitudinal dependent Tikhonov constraint in five zones $\left(90^{\circ} \mathrm{N}-\right.$ $54^{\circ} \mathrm{N}, 54^{\circ} \mathrm{N}-18^{\circ} \mathrm{N}, 18^{\circ} \mathrm{N}-18^{\circ} \mathrm{S}, 18^{\circ} \mathrm{S}-54^{\circ} \mathrm{S}$, and $54^{\circ} \mathrm{S}-$ $90^{\circ} \mathrm{S}$ ) as described by Kulawik et al. (2006), while AIRS OE CO retrievals use a uniform a priori. The DOFS for MOPITT V3 and TES CO agree very well between $65^{\circ} \mathrm{S}$ and $45^{\circ} \mathrm{N}$ and the MOPITT DOFS decreases towards the poles. The latitudinal dependence of the DOFS for MOPITT and TES are largely due to the change in the surface temperature contrasts, while the flatness in the latitudinal dependence of AIRS is maybe partly due to the cloud clearing uncertainties. AIRS OE DOFS are larger than V5 over most of the globe, except the $\mathrm{NH}$ mid-latitude region where the two algorithms are similar. Note that the formulation to compute AIRS V5 DOFS is different from that for the OE and, therefore, the changes of AIRS DOFS between the two algorithms should be understood in a relative sense. Nevertheless, the improvements in the DOFS using OE are mainly in the SH and high latitudes in the $\mathrm{NH}$.
In addition to the uncertainties and errors from different $\mathrm{CO}$ products due to the instrument characteristics and the retrieval algorithms differences, other biases between different sensors exist due to measurement properties such as the time of overpass and the spatial resolutions. MOPITT is on latemorning equator-crossing time (10:30 a.m. local time) and AIRS and TES are on early-afternoon equator-crossing time (01:30 p.m. local time). In general, the retrieved tropospheric CO VMRs are higher when there are higher surface thermal contrasts due to the enhanced sensitivity that samples closer to the sources near the earth's surface. To understand the differences due to the surface thermal contrasts between MOPITT and AIRS CO products requires a thorough analysis and should be a subject of a future study. The effect of spatial resolution differences is best demonstrated by the statistical differences (e.g., biases and SDVs) between AIRS and TES $\mathrm{CO}$. We have studied the PDFs for AIRS and TES CO independently (not shown) and found that the biases are similar for both instruments; however, the SDVs are larger for TES. This is most likely due to the fact that the TES footprints are 


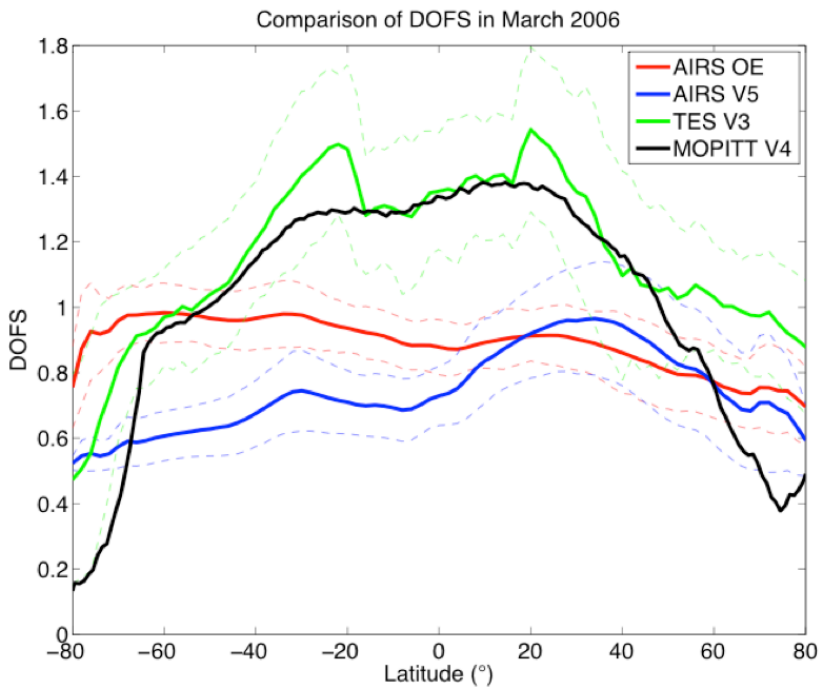

Fig. 9. An example of the DOFS for March 2006 for AIRS V5 CO (blue), AIRS OE CO (red), TES CO (green) and MOPITT CO (black), respectively, where the solid lines are the averaged DOFS in 10-degree latitude bands and the dashed lines represent the maximum and minimum DOFS values in each band.

much smaller, and therefore, the measurements present larger variability. A detailed study in this aspect is also needed, but since this is outside of the scope of this paper, it should be a subject of a future study.

\section{Summary}

We have developed an offline retrieval algorithm for AIRS $\mathrm{CO}$ using the OE technique, similar to that used for MOPITT and TES. This has allowed us to compare the output quantities of the retrieval with the same formulations as MOPITT and TES CO, i.e., CO VMRs, AKs, error covariance, etc., so that we can directly evaluate the performances of the instruments. We have also found that the new algorithm provides more realistic $\mathrm{CO}$ values compared with the in situ measurements and TES and MOPITT CO, and is consistent with prior knowledge of $\mathrm{CO}$ distributions.

Tropospheric CO retrievals from AIRS and TES using the OE method agree to within 5-10 ppbv or 5\% on average globally and throughout the free troposphere. Since this is not the case for the operational products, we conclude that the differences between operational AIRS and TES CO are largely due to the retrieval algorithms rather than the sensor characteristics. The agreements between AIRS OE CO total columns and MOPITT V4 CO total columns have also been improved compared to AIRS operational V5 CO products. We have also showed the instrument DOFS for AIRS, TES, and MOPITT using the same formulation.
Acknowledgements. This study was supported by the NASA Atmospheric Composition Program (NNX07AM45G) and the Global Tropospheric Chemistry Program (NNG06GB04G). We acknowledge the AIRS, TES, and MOPITT Science Teams for the satellite products used in this study. We also acknowledge the INTEX-B Science Team for providing high quality in situ measurements.

Edited by: W. Lahoz

\section{References}

Aumann, H. H., Chahine, M. T., Gautier, C., Goldberg, M., Kalnay, E., McMillin, L., Revercomb, H., Rosenkranz, P. W., Smith, W. L., Staelin, D., Strow, L., and Susskind, J.: AIRS/AMSU/HSB on the Aqua Mission: Design, Science Objectives, Data Products and Processing Systems, IEEE Trans. Geosci. Remote Sens., 41, 253-264, 2003.

Beer, R.: TES on the Aura mission: scientific objectives, measurements, and analysis overview, IEEE Trans. Geosci. Remote Sens., 44, 1102-1105, 2006.

Brasseur, G. P., Hauglustaine, D. A., Walters, S., Rasch, P. J., Muller, J. F., Granier, C., and Tie, X. X.: MOZART, a global chemical transport model for ozone and related chemical tracers 1. Model description, J. Geophys. Res.-Atmos., 103(D21), 28265-28289, 1998.

Deeter, M. N., Emmons, L. K., Francis, G. L., Edwards, D. P., Gille, J. C., Warner, J. X., Khattatov, B., Ziskin, D., Lamarque, J.-F., Ho, S.-P., Yudin, V., Attie, J.-L., Packman, D., Chen, J., Mao, D., and Drummond, J. R.: Operational Carbon Monoxide Retrieval Algorithm and Selected Results for the MOPITT Instrument. J. Geophys. Res., 108(D14), 4399, doi:10.1029/2002JD003186, 2003.

Deeter, M. N., Edwards, D. P., Gille, J. C., and Drummond, J. R.: Sensitivity of MOPITT observations to carbon monoxide in the lower troposphere, J. Geophys. Res., 112, D24306, doi:10.1029/2007JD008929, 2007.

Deeter, M. N., Edwards, D. P., and Gille, J. C.: Retrievals of carbon monoxide profiles from MOPITT observations using lognormal a priori statistics, J. Geophys. Res., 112, D11311, doi:10.1029/2006JD007999, 2009.

Deeter, M. N., Edwards, D. P., Gille, J. C., Emmons, L. K., Francis, G., Ho, S.-P., Mao, D., Masters, D., Worden, H., Drummond, J. R., and Novelli, P. C.: The MOPITT Version 4 CO Product: Algorithm Enhancements, Validation, and Long-Term Stability, J. Geophys. Res., doi:10.1029/2009jd013005, 2010.

Drummond, J. R.: Novel correlation radiometer: The length modulated radiometer, Appl. Opt., 28, 2451-2452, 1989.

Edwards, D. P., Emmons, L. K., Gille, J. C., Chu, A., Atti, J.-L., Giglio, L., Wood, S. W., Haywood, J., Deeter, M. N., Massie, S. T., Ziskin, D. C., and Drummond, J. R.: Satellite-observed pollution from Southern Hemisphere biomass burning, J. Geophys. Res., 111, D14312, doi:10.1029/2005JD006655, 2006.

El Amraoui, L., Atti, J.-L., Semane, N., Claeyman, M., Peuch, V.H., Warner, J., Ricaud, P., Cammas, J.-P., Piacentini, A., Josse, B., Cariolle, D., Massart, S., and Bencherif, H.: Midlatitude stratosphere - troposphere exchange as diagnosed by MLS O3 
and MOPITT CO assimilated fields, Atmos. Chem. Phys., 10, 2175-2194, doi:10.5194/acp-10-2175-2010, 2010.

Emmons, L. K., Deeter, M. N., Gille, J. C., Edwards, D. P., Attie, J.-L., Warner, J. Ziskin, D., X., Francis, G. L., Khattatov, B., Yudin, V., Lamarque, J.-F., Ho, S.-P., Mao, D., Chen, J., Drummond, J. R., Novelli, P. C., Sachse, G., Coffey, M. T., Hannigan, J. W., Gerbig, C., Kawakami, S., Kondo, Y., Takegawa, N., Schlager, H., Baehr, J., and Ziereis, H.: Validation of Measurements of Pollution in the Troposphere (MOPITT) CO retrievals with aircraft in situ profiles, J. Geophys. Res., 109, D03309, doi:10.1029/2003JD004101, 2004.

Emmons, L. K., Pfister, G. G., Edwards, D. P., Gille, J. C., Sachse, G., Blake, D., Wofsy, S., Gerbig, C., Matross, D., and Ne de lec, P.: Measurements of Pollution in the Troposphere (MOPITT) validation exercises during summer 2004 field campaigns over North America, J. Geophys. Res., 112, D12S02, doi:10.1029/2006JD007833, 2007.

Emmons, L. K., Edwards, D. P., Deeter, M. N., Gille, J. C., Campos, T., Nédélec, P., Novelli, P., and Sachse, G.: Measurements of Pollution In The Troposphere (MOPITT) validation through 2006, Atmos. Chem. Phys., 9, 1795-1803, doi:10.5194/acp-91795-2009, 2009.

Fisher, J. A., Jacob, D. J., Purdy, M. T., Kopacz, M., Le Sager, P., Carouge, C., Holmes, C. D., Yantosca, R. M., Batchelor, R. L., Strong, K., Diskin, G. S., Fuelberg, H. E., Holloway, J. S., Hyer, E. J., McMillan, W. W., Warner, J., Streets, D. G., Zhang, Q., Wang, Y., and Wu, S.: Source attribution and interannual variability of Arctic pollution in spring constrained by aircraft (ARCTAS, ARCPAC) and satellite (AIRS) observations of carbon monoxide, Atmos. Chem. Phys., 10, 977-996, doi:10.5194/acp-10-977-2010, 2010.

Ho, S., Edwards, D. P., Gille, J. C., Luo, M., Osterman, G. B., Kulawik, S. S., and Worden, H.: A global comparison of carbon monoxide profiles and column amounts from Tropospheric Emission Spectrometer (TES) and Measurements of Pollution in the Troposphere (MOPITT), J. Geophys. Res., 114, D21307, doi:10.1029/2009JD012242, 2009.

Kopacz, M., Jacob, D. J., Fisher, J. A., Logan, J. A., Zhang, L., Megretskaia, I. A., Yantosca, R. M., Singh, K., Henze, D. K., Burrows, J. P., Buchwitz, M., Khlystova, I., McMillan, W. W., Gille, J. C., Edwards, D. P., Eldering, A., Thouret, V., and Nédélec, P.: Global estimates of CO sources with high resolution by adjoint inversion of multiple satellite datasets (MOPITT, AIRS, SCIAMACHY, TES), Atmos. Chem. Phys., 10, 855-876, doi:10.5194/acp-10-855-2010, 2010.

Kulawik, S. S., Osterman, G., Jones, D. B. A., and Bowman, K. W.: Calculation of altitude-dependent Tikhonov constraints for TES nadir retrievals, IEEE Trans. Geosci. Remote Sens., 44, 13341342, doi:10.1109/TGRS.2006.871206, 2006.

Lamarque J.-F., Khattatov, B., Yudin, V., Edwards, D. P., Gille, J. C., Emmons, L. K., Deeter, M. N., Warner, J., Ziskin, D., Francis, G., Ho, S., Mao, D., and Chen, J.: Application of a bias estimator for the improved assimilation of Measurements of Pollution in the Troposphere (MOPITT) carbon monoxide retrievals, J. Geophys. Res., 109, D16304, doi:10.1029/2003JD004466, 2004.

Luo, M., Rinsland, C., Fisher, B., Sachse, G., Diskin, G., Logan, J., Worden, H., Kulawik, S., Osterman, G., Eldering, A., Herman, R., and Shephard, M.: TES carbon monoxide validation with
DACOM aircraft measurements during INTEX-B 2006, J. Geophys. Res., 112, D24S48, doi:10.1029/2007JD008803, 2007.

Luo, M., Rinsland, C. P., Rodgers, C. D., Logan, J. A., Worden, H., Kulawik, S., Eldering, A., Goldman, A., Shephard, M. W., Gunson, M., and Lampel, M. C.: Comparison of car- bon monoxide measurements by TES and MOPITT: Influence of a priori data and instrument characteristics on nadir atmospheric species retrievals, J. Geophys. Res., 112, D09303, doi:10.1029/2006JD007663, 2007.

Maddy, E. S. and Barnet, C. D.: Vertical resolution estimates in Version 5 of AIRS operational retrievals, IEEE Trans. Geosci. Remote Sens., 46(8), 2375-2384, 2008.

McMillan, W. W., Barnet, C., Strow, L., M. Chahine, Warner, J., McCourt, M., Novelli, P., Korontzi, S., Maddy, E., and Datta, S.: Daily Global Maps of Carbon Monoxide from NASA's Atmospheric InfraRed Sounder, Geophys. Res. Lett., 32, L11801, doi:10.1029/2004GL021821, 2005.

Nam, J., Wang, Y., Luo, C., and Chu, D. A.: Trans-Pacific transport of Asian dust and CO: accumulation of biomass burning $\mathrm{CO}$ in the subtropics and dipole structure of transport, Atmos. Chem. Phys., 10, 3297-3308, doi:10.5194/acp-10-3297-2010, 2010.

Pan, L., Gille, J. C., Edwards, D. P., Bailey, P. L., and Rodgers, C. D.: Retrieval of tropospheric carbon monoxide for the mopitt experiment, J. Geophys. Res., 103, 32277-32290, 1998.

Pfister, G. G., Emmons, L. K., Edwards, D. P., Arellano, A., G Sachse, and Campos, T.: Variability of springtime transpacific pollution transport during 20002006: the INTEX-B mission in the context of previous years, Atmos. Chem. Phys., 10, 13451359, doi:10.5194/acp-10-1345-2010, 2010.

Rodgers, C. D.: Inverse Methods for Atmospheric Sounding, Theory and Practice, Ser. Atmos. Oceanic Planet. Phys., 2, World Sci., Hackensack, NJ, USA, 2000.

Rodgers, C. D., and Connor, B. J.: Intercomparison of remote sounding instruments, J. Geophys. Res., 108 4116, doi:10.1029/2002JD002299, 2003.

Sachse, G. W., Hill, G. F., Wade, L. O., and Perry, M. G.: Fastresponse, high-precision carbon monoxide sensor using a tunable diode laser absorption technique, J. Geophys. Res., 92, 20712081, 1987.

Singh, H. B., Brune, W. H., Crawford, J. H., Jacob, D. J., and Russell, P. B.: Overview of the summer 2004 Intercontinental Chemical Transport Experiment-North America (INTEX-A), J. Geophys. Res., 111, D24S01, doi:10.1029/2006JD007905, 2006.

Singh, H. B., Brune, W. H., Crawford, J. H., Flocke, F., and Jacob, D. J.: Chemistry and transport of pollution over the Gulf of Mexico and the Pacific: spring 2006 INTEX-B campaign overview and first results, Atmos. Chem. Phys., 9, 2301-2318, doi:10.5194/acp-9-2301-2009, 2009.

Sparling, L. C.: Statistical Perspectives on Stratospheric Transport, Rev. Geophys., 38(3), 417-436, doi:10.1029/1999RG000070, 2000.

Stohl, A., Berg, T., Burkhart, J. F., Fjǽraa, A. M., Forster, C., Herber, A., Hov, Ø., Lunder, C., McMillan, W. W., Oltmans, S., Shiobara, M., Simpson, D., Solberg, S., Stebel, K., Ström, J., Tørseth, K., Treffeisen, R., Virkkunen, K., and Yttri, K. E.: Arctic smoke - record high air pollution levels in the European Arctic due to agricultural fires in Eastern Europe in spring 2006, Atmos. Chem. Phys., 7, 511-534, doi:10.5194/acp-7-511-2007, 2007. 
Strow, L., Hannon, S., Machado, S., Motteler, H., and Tobin, D.: An Overview of the AIRS Radiative Transfer Model, IEEE Trans. Geosci. Remote Sens., 41, 303-313, 2003.

Susskind, J., Barnet, C. D., and Blaisdell, J. M.: Retrieval of atmospheric and surface parameters from AIRS/AMSU/HSB data in the presence of clouds, IEEE Trans. on Geosci. Remote Sens., 41, 390-409, 2003.

Tangborn, A., Stajner, I., Buchwitz, M., Khlystova, I., Pawson, S., Burrows, J., Hudman, R., and Nedelec, P.: Assimilation of SCIAMACHY CO observations: Global and regional analysis of data impact, J. Geophys. Res., 114, D07307, doi:10.1029/2008JD010781, 2009.

Turquety, S., Clerbaux, C., Law, K., Coheur, P.-F., Cozic, A., Szopa, S., Hauglustaine, D. A., Hadji-Lazaro, J., Gloudemans, A. M. S., Schrijver, H., Boone, C. D., Bernath, P. F., and Edwards, D. P.: $\mathrm{CO}$ emission and export from Asia: an analysis combining complementary satellite measurements (MOPITT, SCIAMACHY and ACE-FTS) with global modeling, Atmos. Chem. Phys., 8, 5187-5204, doi:10.5194/acp-8-5187-2008, 2008.
Warner, J. X., Comer, M. M., Barnet, C. D., McMillan, W. W., Wolf, W., Maddy, E., Sachse, G.: A Comparison of Satellite Tropospheric Carbon Monoxide Measurements from AIRS and MOPITT During INTEX-A, J. Geophys. Res., doi:10.1029/2006JD007925, 2007.

Worden, J., Sund-Kulawik, S., Shephard, M. W., Clough, S. A., Worden, H., Bowman, K., and Goldman, A.: Predicted errors of tropospheric emission spectrometer nadir retrievals from spectral window selection, J. Geophys. Res., 109(D9), D09308, doi:10.1029/2004JD004522, 2004.

Yurganov, L. N., McMillan, W. W., Dzhola, A. V., Grechko, E. I., Jones, N. B., and van der Werf, G. R.: Global AIRS and MOPITT CO measurements: Validation, comparison, and links to biomass burning variations and carbon cycle, J. Geophys. Res., 113(D9), doi:10.1029/2007JD009229, 2008.

Zhang, L., Jacob, D. J, Bowman, K. W.: Ozone-CO correlations determined by the TES satellite instrument in continental outflow regions, Geophys. Res. Lett., 33, L18804, doi:10.1029/2006GL026399, 2006. 